\title{
Ethnic differences in unemployment and ill health
}

\author{
Merel Schuring • Alex Burdorf • Anton Kunst • \\ Toon Voorham · Johan Mackenbach
}

Received: 4 September 2008 / Accepted: 6 February 2009 / Published online: 22 February 2009

(C) The Author(s) 2009. This article is published with open access at Springerlink.com

\begin{abstract}
Objective The aim of the study is to evaluate whether health inequalities associated with unemployment are comparable across different ethnic groups.

Method A random sample of inhabitants of the city of Rotterdam filled out a questionnaire on health and its determinants, with a response of $55.4 \%(n=2,057)$. In a cross-sectional design the associations of unemployment, ethnicity, and individual characteristics with a perceived poor health were investigated with logistic regression analysis. The associations of these determinants with physical and mental health, measured by the Short Form 36 Health Survey, were evaluated with linear regression analyses. Interactions between ethnicity and unemployment were investigated to determine whether associations of unemployment and health differed across ethnic groups.

Results Ill health was more common among unemployed persons [odds ratio (OR) 2.6; 95\% CI 1.7-3.8] than workers in paid employment. Health inequalities between employed and unemployed persons were largest among native Dutch persons $(\mathrm{OR}=3.2)$ and Surinamese/Antillean persons $(\mathrm{OR}=2.6)$, and smaller in Turkish/Moroccan persons $(\mathrm{OR}=1.6)$ and overseas refugees $(\mathrm{OR}=1.6)$. The proportions of persons with poor health that could be attributed to unemployment were 14, 26, 14, and $13 \%$, respectively.
\end{abstract}

M. Schuring · A. Burdorf $(\bowtie) \cdot$ A. Kunst $\cdot$ J. Mackenbach Department of Public Health, Erasmus MC, PO Box 2040, 3000 CA Rotterdam, The Netherlands

e-mail: a.burdorf@erasmusmc.nl

T. Voorham

Municipal Health Authority Rotterdam Area, Rotterdam,

The Netherlands
Conclusions Differences in ill health between employed and unemployed persons were less profound in ethnic groups compared to the majority population, but the prevalence of unemployment was much higher in ethnic groups. The population attributable fractions varied between 14 and 28\%, supporting the argument that policies for health equity should pay more attention to measures that include persons in the labour market and that prevent workers with ill health from dropping out of the workforce.

Keywords Ethnicity · Inequalities · Unemployment · Perceived health

\section{Introduction}

The presence of socioeconomic inequalities in health has been widely acknowledged. Lower education, unskilled labour, and a low income are associated with higher mortality and morbidity (Marmot et al. 1991). Labour force participation is an important determinant of health inequalities, as demonstrated by a higher prevalence of illness (Claussen 1999) and disability (Janlert 1997) and a higher mortality among unemployed persons (Morris et al. 1994). A poor health is strongly associated with non-participation in the labour force, both unemployment and disability (Alavinia and Burdorf 2008; Boot et al. 2008). The association between health and employment is bi-directional: unemployment may cause poor health (causation hypothesis), and poor health may increase the probability of becoming unemployed (selection hypothesis) (Bartley et al. 2004; Schuring et al. 2007).

Within many countries, substantial inequalities in health between ethnic groups exist (Smith et al. 2000; 
Bos et al. 2004). The extent to which socioeconomic inequalities underlie ethnic inequalities in health remains debated. Many researchers argue that ethnic inequalities in health are predominantly determined by socioeconomic inequalities (Nazroo 2003; Chandola 2001). Others argue that ethnicity is an independent risk factor for self-reported illness, with an importance equal to risk factors such as social class, age, having a poor social network, not taking regular exercise, and not feeling secure in daily life (Sundquist 1995). When the strength of the relation between socioeconomic status and health varies across ethnic groups, this will have consequences for the extent to which socioeconomic inequalities can underlie ethnic differences in health. A Canadian study found that socioeconomic factors were more important to self-rated health status and presence of chronic illness among immigrants than in non-immigrants (Dunn and Dyck 2000). There are some indications from a German study that unemployed foreign workers were less satisfied with their health than unemployed Germans (Elkeles and Seifert 1996). Schuring et al. (2007) observed that in countries with a low national unemployment rate, poor health was strongly associated with entering or retaining paid employment, whereas in countries with a high national unemployment rate the effect of poor health on selection in and out of the workforce was much smaller. A possible explanation is that with high unemployment various factors determine labour opportunities, such as education, training, and age, and that a poor health only plays a minor role relative to these socio-demographic factors (Fayers and Sprangers 2002). With low unemployment persons of all ages and educational levels are retained in the workforce, and thus the influence of poor health becomes more prominent. This reasoning would imply that, within a given country, among those groups with high unemployment, such as minority groups, sociodemographic factors will exceed the importance of health. Hence, a high unemployment rate in minority groups may mask the association between health and employment status in these groups.

In order to better understand the relation between ethnicity, socioeconomic status and health, it is important to assess whether socioeconomic status is associated with health in a similar way across ethnic groups. In this paper we examine the associations between unemployment and health in the three largest ethnic minority groups of the Netherlands and the indigenous population. The aims of the study were (1) to evaluate whether the associations between poor health and employment status are less strong among ethnic groups with high unemployment than among Dutch persons and (2) to assess the differences in proportions of unemployment attributed to poor health.

\section{Methods}

Population

Between March and June 2003 a health questionnaire survey was undertaken by the municipal health service of Rotterdam in a random sample of 6,404 inhabitants of the city of Rotterdam, aged 16-84 (Kuilman et al. 2005). A questionnaire was sent to the home address, followed by two reminders, 2 and 4 weeks later, respectively. A total of 3,406 subjects returned the questionnaire (response 55.4\%). Those respondents who were aged between 16 and 65 years and not engaged as students in a secondary or tertiary educational programme were selected for the current study with a cross-sectional design. A total of 2,057 subjects met these inclusion criteria.

\section{Socio-demographic variables}

The socio-demographic variables included in this study were labour force participation, ethnic background, highest educational level, age, sex, and marital status. In this study, labour status was based on self-reported current economic status with five mutually exclusive categories: full-time employment ( $>32 \mathrm{~h} /$ week), part-time employment $(<32 \mathrm{~h} /$ week), unemployment, disability pension, and homemaker.

The ethnic background of the respondent was based on the country of origin of the mother. In case the mother was born in The Netherlands, the country of birth of the father was leading (CBS 2003). Different ethnic groups were defined, based on differences in experiences of migration (refugees or labour migrants) and differences in geographical and cultural distance from the Netherlands. Three ethnic minority groups were defined: (1) Turks and Moroccans, (2) Antilleans and Surinamese, and (3) refugees. Turks and Moroccans initially came as labour migrants to the Netherlands from the early 1960s, while the migration of Surinamese and Antilleans/Arubans is related to the colonial past. Refugees are another important group of migrants from designated countries such as Afghanistan, Algeria, Angola, Bosnia, China, Chile, Croatia, Democratic Republic of the Congo, Eritrea, Hong Kong, Iran, Iraq, Kosovo, Liberia, Nigeria, Sudan, Serve, Sierra Leone, Somalia, South Korea, Syria and former Yugoslavia. Immigrants from other countries were not included in the analysis $(n=296)$.

Subjects were divided into three groups according to their highest level of educational attainment. A high educational level was defined as higher vocational training or university; an intermediate educational level was defined as higher secondary schooling or intermediate vocational training, and a low educational level was defined as no education, primary school, lower and intermediate secondary 
schooling or lower vocational training. Marital status was used to distinguish those subjects married or living together with others.

\section{Health measures}

Self-reported health (SRH) was measured by asking subjects to rate their overall health on a 5-point scale, ranging from 'excellent', 'very good', 'good' and 'fair' to 'poor'. Those reporting less than 'good health' were defined as having a poor health (Fayers and Sprangers 2002). Health was also measured with the Dutch version of the Short Form 36 Health Survey (SF-36) (Ware and Sherbourne 1992). The SF-36 consists of 36 items that were used to calculate scores on eight dimensions: physical functioning, general health, mental health, bodily pain, social functioning, vitality, role limitation due to emotional health problems, and role limitation due to physical health problems. Scores could range from 0 to 100 , with a higher score indicating a better health related quality of life.

\section{Statistical analysis}

Characteristics of subjects were analysed using descriptive statistics. For two subscales of the SF-36, role limitations due to physical health problems and role limitations due to emotional health problems, a strong ceiling effect existed and the variables were not normally distributed. Therefore, these subscales were excluded from further analysis.

The statistical analyses were conducted on the study population with complete information on all variables included in the multivariate analyses. Since the educational level was not available for 207 subjects (10\%) and for other variables, a few missing values occurred, the number of subjects in the analyses may vary slightly. The associations between unemployment, ethnicity and other socio-demographic characteristics and perceived poor health were investigated with logistic regression analysis, with the odds ratio (OR) as a measure of association. The analysis started with univariate logistic regression models to determine which independent variables were of interest to consider in the final model. Variables with a $P$ value of at least 0.10 were selected for further analysis. A multivariate logistic regression analysis was conducted to determine the association of employment status, ethnic background, sex, age, educational level, and marital status with the dichotomous outcome measure of poor health. Explanatory variables were included into the main model one by one by a forward selection procedure, in order of magnitude of explained variance in the univariate analyses, and independent variables with a $P$ value of at least 0.05 were retained in the model. Interaction effects between ethnicity and unemployment were analysed in order to determine whether the effects of unemployment on health differed across ethnic groups. The proportion of persons with poor health that theoretically could be attributed to unemployment was calculated with the population attributable fraction (PAF), expressed by the formula PAF\% $=100 \times[p \times(\mathrm{OR}-1)] /$ $[1+p \times(\mathrm{OR}-1)]$, whereby $p$ is the proportion of unemployed persons and the OR is the association between unemployment and poor health (Last 2001).

The associations of labour status, ethnicity, and other socio-demographic characteristics with physical and mental health were investigated with multiple linear regression analyses, with as dependent variables the scores on the six subscales of the SF-36; general health, physical health, bodily pain, mental health, social functioning, and vitality.

All statistical analyses were performed with the statistical package SPSS 11.0 for Windows.

\section{Results}

Characteristics of subjects are presented in Table 1, stratified by ethnic background. Immigrant subjects were younger of age, more often unemployed and, with the exception of refugees, lower educated than native Dutch subjects. Subjects with a Turkish or Moroccan background were more often married and homemaker compared with the other ethnic groups. Health status was lower in migrants than native Dutch subjects for most dimensions of health. Turkish and Moroccan subjects had the worst health, whereas the health status of refugees resembled that of native Dutch subjects for some dimensions of health.

Figure 1 shows that within each ethnic group, with the exception of refugees, unemployed subjects had a worse health than employed subjects. Subjects with a disability pension had the worst health in every ethnic group. Among subjects with a Turkish or Moroccan background the health status of homemakers was equal to the health status of unemployed subjects.

Table 2 shows that all socio-demographic variables in this study were included in the multivariate model. Migrants more often had a poor health than native Dutch subjects, even after adjusting for age, gender, educational level, marital status, and labour force participation. The health status of Turkish or Moroccan subjects was the worst $[\mathrm{OR}=3.9(2.6-6.0)]$, whereas the health status of refugees was not significantly different $[\mathrm{OR}=1.8(0.9-3.3)]$ from that of native Dutch subjects.

Table 3 describes the associations with health-related quality of life, which resembles the pattern observed for a perceived poor health in Table 2. All migrant groups had significantly lower scores for the physical as well as the mental health dimensions of the SF-36 than the native Dutch group, indicating a poorer health. Unem- 
Table 1 Characteristics and perceived health of subjects with different ethnic backgrounds in a community-based health survey in the Netherlands $(n=2,057)$

* Chi-square test $P<0.05$ comparing minority groups to the native Dutch population

\begin{tabular}{|c|c|c|c|c|}
\hline & $\begin{array}{l}\text { Dutch } \\
n=1,448\end{array}$ & $\begin{array}{l}\mathrm{T} / \mathrm{M} \\
n=228\end{array}$ & $\begin{array}{l}\text { S/A } \\
n=281\end{array}$ & $\begin{array}{l}\text { Refugee } \\
n=100\end{array}$ \\
\hline Women & $808(55.9 \%)$ & $119(52.2 \%)$ & $170(60.5 \%)$ & $50(50.0 \%)$ \\
\hline \multicolumn{5}{|l|}{ Age* } \\
\hline $18-24$ years & $96(6.6 \%)$ & $34(14.9 \%)$ & $39(13.9 \%)$ & $13(13.0 \%)$ \\
\hline 25-44 years & $662(45.7 \%)$ & $137(60.1 \%)$ & $145(51.6 \%)$ & $54(54.0 \%)$ \\
\hline $45-54$ years & $347(24.0 \%)$ & $31(13.6 \%)$ & $68(24.2 \%)$ & $19(19.0 \%)$ \\
\hline $55-65$ years & $343(23.7 \%)$ & $26(11.4 \%)$ & $29(10.3 \%)$ & $14(14.0 \%)$ \\
\hline Married* & $882(61.8 \%)$ & $168(74.3 \%)$ & $113(40.8 \%)$ & $56(57.1 \%)$ \\
\hline \multicolumn{5}{|l|}{ Educational level* } \\
\hline High & $394(28.7 \%)$ & $10(6.3 \%)$ & $24(10.0 \%)$ & $18(22.5 \%)$ \\
\hline Intermediate & $350(25.5 \%)$ & $42(26.4 \%)$ & $59(24.7 \%)$ & $30(37.5 \%)$ \\
\hline Low & $628(45.8 \%)$ & $107(67.3 \%)$ & $156(65.3 \%)$ & $32(40.0 \%)$ \\
\hline Missing & 76 & 69 & 42 & 20 \\
\hline \multicolumn{5}{|l|}{ Employment status* } \\
\hline Employed >32 h/week & $812(56.1 \%)$ & $83(36.4 \%)$ & $139(49.5 \%)$ & $51(51.0 \%)$ \\
\hline Employed <32 h/week & $289(20.0 \%)$ & $28(12.3 \%)$ & $56(19.9 \%)$ & $13(13.0 \%)$ \\
\hline Unemployed & $111(7.7 \%)$ & $60(26.3 \%)$ & $63(22.4 \%)$ & $25(25.0 \%)$ \\
\hline Disability pension & $111(7.7 \%)$ & $14(6.1 \%)$ & $13(4.6 \%)$ & $3(3.0 \%)$ \\
\hline Homemaker & $125(8.6 \%)$ & $43(18.9 \%)$ & $10(3.6 \%)$ & $8(8.0 \%)$ \\
\hline Poor health* & $261(18.1 \%)$ & $97(42.7 \%)$ & $88(31.7 \%)$ & $21(21.0 \%)$ \\
\hline General health* & $70.1(19.7)$ & $55.7(22.8)$ & $63.3(20.6)$ & $65.5(19.5)$ \\
\hline Physical functioning* & $87.4(19.9)$ & $69.1(27.0)$ & $78.8(25.8)$ & $79.2(26.3)$ \\
\hline Social functioning* & $81.7(23.2)$ & $69.4(24.7)$ & $73.7(27.2)$ & $75.9(24.6)$ \\
\hline Bodily pain* & $78.7(24.2)$ & $65.1(28.3)$ & $72.2(26.6)$ & $73.5(24.7)$ \\
\hline Vitality* & $62.6(19.2)$ & $50.6(18.0)$ & $54.9(18.9)$ & $55.0(18.9)$ \\
\hline Mental health* & $73.9(17.6)$ & $61.8(18.8)$ & $68.3(20.6)$ & $66.4(18.0)$ \\
\hline Role limitations, physical* & $80.2(34.5)$ & $66.3(36.9)$ & $77.5(35.0)$ & $80.6(31.6)$ \\
\hline Role limitations, emotional* & $84.7(32.1)$ & $69.8(39.6)$ & $78.8(37.2)$ & $81.4(33.8)$ \\
\hline
\end{tabular}

Fig. 1 Perceived health of subjects with different ethnic backgrounds in a community-based health survey in the Netherlands $(n=2,057)$ specified for different categories of labour force participation or being out of the workforce

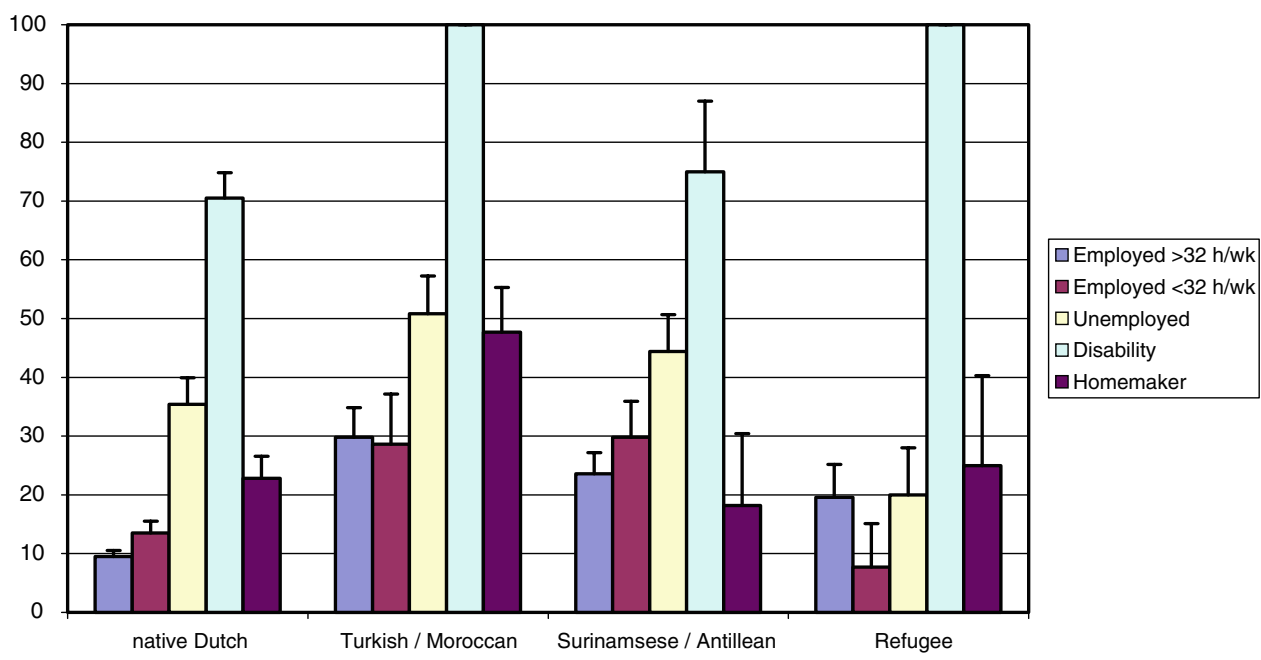

ployed persons and persons receiving a disability pension had significantly lower scores for all dimensions of physical and mental health compared with employed persons. The magnitude of these differences was comparable to the observed differences in health across age and education.

The interaction between employment status and ethnic background had a significant contribution to the logistic 
Table 2 Associations between demographic factors and employment status with poor health of subjects with different ethnic backgrounds in a community-based health survey in the Netherlands $(n=1,815)$ by multivariate logistic regression analysis

\begin{tabular}{lrl}
\hline & $n$ & OR $(95 \% \mathrm{CI})$ \\
\hline Native Dutch & 1,346 & 1.0 \\
Turkish/Moroccan & 157 & $3.9(2.6-6.0)$ \\
Surinamese/Antillean & 233 & $2.5(1.7-3.6)$ \\
Refugee & 79 & $1.8(0.9-3.3)$ \\
Age & & \\
18-24 years & 143 & 1.0 \\
25-44 years & 886 & $2.4(1.3-4.3)$ \\
45-55 years & 417 & $5.5(2.9-10.4)$ \\
55-64 years & 369 & $4.7(2.5-9.1)$ \\
Women & 1,016 & $1.6(1.2-2.1)$ \\
Educational level & & \\
High & 443 & 1.0 \\
Intermediate & 473 & $1.6(1.0-2.5)$ \\
Low & 899 & $3.2(2.1-4.9)$ \\
Married & 1,106 & $1.4(1.0-1.8)$ \\
Employment status & & \\
Employed $>32 \mathrm{~h} /$ week & 996 & 1.0 \\
Employed $<32 \mathrm{~h} /$ week & 349 & $1.0(0.7-1.5)$ \\
Unemployed & 194 & $2.6(1.7-3.8)$ \\
Disability pension & 119 & $14.4(8.8-23.6)$ \\
Homemaker & 157 & $1.1(0.7-1.8)$ \\
\hline$O R$ od & &
\end{tabular}

$O R$ odds ratio, $C I$ confidence interval

regression model $\left(\chi^{2}=10.4 ; d f=3 ; P=0.018\right)$, demonstrating that the associations between employment status and health varied within ethnic groups (Table 4). Health inequalities between employed and unemployed subjects were largest among the Dutch subjects $[\mathrm{OR}=3.2(1.9$ 5.4)], followed by Surinamese and Antilleans $[\mathrm{OR}=2.6$ (1.3-5.2)], and less pronounced among Turkish/Moroccan subjects $[\mathrm{OR}=1.6(0.7-3.7)]$ and refugees $[\mathrm{OR}=1.6(0.4-$ 6.2)]. The PAF of unemployment in poor health was $14 \%$ among Dutch, 26\% in Surinamese and Antilleans, 14\% among Turkish and Moroccan, and 13\% among refugees.

\section{Discussion}

Ill health was substantially more common among unemployed persons than workers in paid employment. Health inequalities associated with employment differed within ethnic groups, with the strongest association between employment and health for native Dutch persons, followed by Surinamese and Antilleans and a less pronounced association between employment and health for Turkish/ Moroccan persons and refugees. The PAF varied between
13 and $26 \%$, indicating that employment status is an important factor in socioeconomic health inequalities.

The design of this study was cross-sectional, and therefore no assumption can be made about the direction of the association between poor health and unemployment among migrant groups. Unemployment may cause poor health and poor health may increase the probability of becoming unemployed (Bartley et al. 2004; Schuring et al. 2007). Another limitation of this study was the lack of information on non-respondents. With respect to unemployment in the study population, the proportion of unemployed persons within each ethnic group resembled closely the registered unemployment in the city of Rotterdam, and thus the response does not seem biased towards employed or unemployed persons.

In this study ethnic groups reported higher prevalences of poor health and also lower scores on health-related quality of life. There is a widespread agreement that a single question asking subjects to rate their overall health on a scale from excellent to poor provides a useful summary of how subjects perceive their overall health status (Fayers and Sprangers 2002). However, the validity of this singleitem question in subjects with different cultural backgrounds has been questioned (Agyemang et al. 2006). Differences in self-concepts between ethnic groups may influence the results of the single item general health question. The observation that after adjusting for the well-established socio-demographic determinants of health inequalities, still systematic differences in occurrence of poor health in ethnic groups relative to the Dutch group were observed may indicate over-estimation of poor health. In the current study similar conclusions on unemployed, ethnicity, and health were drawn when using the single question on perceived general health question and the other 35 questions on physical and mental health dimensions of the SF-36. This corroborates the opinion that the general health question provides a good summery of the mental and physical health in migrant groups and the indigenous population. This finding is, of course, also supported by the high correlations between perceived general health and all health dimensions in the SF-36.

A high proportion of persons with a poor health among ethnic groups has been observed in various studies in different countries (Bos et al. 2004; Chandola 2001; Smith et al. 2000; Nazroo 2003; Sundquist 1995). Different explanations have been put forward. A Swedish study among immigrants from Poland, Turkey, and Iran found that acculturation (defined by the knowledge of the Swedish language) was an important mediator in the pathway between ethnicity and poor health (Wiking et al. 2004). Indeed, in our study population differences in mastering the Dutch language may have influenced health. For Surinamese and Antilleans Dutch is usually a first or second language, 
Table 3 Associations between demographic factors and employment status with health related quality of life (six subscales of the SF-36) of subjects with different ethnic backgrounds in a community-based

\begin{tabular}{|c|c|c|c|c|c|c|}
\hline & General health & Physical functioning & Bodily pain & Mental health & Social functioning & Vitality \\
\hline Intercept & $81.8(2.3)$ & $102.4(2.4)$ & $100.0(2.9)$ & $82.9(2.2)$ & $97.5(2.8)^{*}$ & $77.5(2.3)^{*}$ \\
\hline Native Dutch & 0 & 0 & 0 & 0 & 0 & 0 \\
\hline Turkish/Moroccan & $-11.0(1.6)^{*}$ & $-13.1(1.7)^{*}$ & $-9.6(2.0)^{*}$ & $-8.2(1.5)^{*}$ & $-9.5(2.0)^{*}$ & $-7.3(1.6)^{*}$ \\
\hline Surinamese/Antillean & $-6.5(1.4)^{*}$ & $-8.2(1.4)^{*}$ & $-5.0(1.7)^{*}$ & $-3.9(1.3)^{*}$ & $-7.3(1.6)^{*}$ & $-5.5(1.4)^{*}$ \\
\hline Refugee & $-4.5(2.2)^{*}$ & $-7.0(2.3)^{*}$ & $-6.5(2.7)^{*}$ & $-5.9(2.0)^{*}$ & $-6.6(2.6)^{*}$ & $-7.5(2.1)^{*}$ \\
\hline \multicolumn{7}{|l|}{ Age } \\
\hline 18-24 years & 0 & 0 & 0 & 0 & 0 & 0 \\
\hline $25-44$ years & $-1.7(1.7)$ & $1.0(1.7)$ & $-2.2(2.1)$ & $-0.2(1.6)$ & $-2.4(2.0)$ & $-3.5(1.6)^{*}$ \\
\hline $45-54$ years & $-5.5(1.8)^{*}$ & $-4.2(1.9)^{*}$ & $-7.1(2.3)^{*}$ & $-0.3(1.7)$ & $-3.9(2.2)$ & $-3.0(1.8)$ \\
\hline $55-64$ years & $-6.6(1.9)^{*}$ & $-6.0\left(1.9^{*}\right.$ & $-4.9(2.3)^{*}$ & $-1.6(1.8)$ & $-2.7(2.3)$ & $-2.5(1.8)$ \\
\hline Women & $-1.4(1.0)$ & $-2.9(1.0)^{*}$ & $-6.6(1.2)^{*}$ & $-2.8(0.9)^{*}$ & $-4.9(1.2)^{*}$ & $-4.3(1.0)^{*}$ \\
\hline \multicolumn{7}{|l|}{ Educational level } \\
\hline High & 0 & 0 & 0 & 0 & 0 & 0 \\
\hline Intermediate & $-1.9(1.2)$ & $-1.9(1.3)$ & $-3.5(1.5)^{*}$ & $-0.5(1.1)$ & $-1.0(1.5)$ & $-1.3(1.2)$ \\
\hline Low & $-6.1(1.2)^{*}$ & $-8.7(1.2)^{*}$ & $-7.2(1.5)^{*}$ & $-4.4(1.1)^{*}$ & $-4.0(1.4)^{*}$ & $-6.1(1.1)^{*}$ \\
\hline Employed >32 h/week & 0 & 0 & 0 & 0 & 0 & 0 \\
\hline Employed <32 h/week & $0.2(1.2)$ & $-1.1(1.3)$ & $-0.3(1.6)$ & $-0.1(1.2)$ & $-1.3(1.5)$ & $-1.1(1.2)$ \\
\hline Unemployed & $-7.7(1.5)^{*}$ & $-4.7(1.6)^{*}$ & $-8.8(1.9)^{*}$ & $-10.5(1.4)^{*}$ & $-9.3(1.8)^{*}$ & $-7.3(1.5)^{*}$ \\
\hline Disability pension & $-28.3(1.9)^{*}$ & $-33.2(2.0)^{*}$ & $-29.3(2.3)^{*}$ & $-16.1(1.8)^{*}$ & $-31.9(2.3)^{*}$ & $-19.3(1.9)^{*}$ \\
\hline Homemaker & $-1.0(1.8)$ & $-3.1(1.9)$ & $-0.09(2.2)$ & $0.6(1.7)$ & $1.0(2.1)$ & $0.04(1.7)$ \\
\hline
\end{tabular}

health survey in the Netherlands $(n=1,845)$ by multivariate linear regression analysis

$* P<0.05$

whereas for Turks and Moroccans knowledge of the Dutch language is often limited or absent, especially among older women. Language problems may hamper effective communication with physicians and also inhibit access to information on health and health care (Uniken Venema et al. 1995). In the current study, mastery of the Dutch language was not included in the analyses, but the observation that the health status of homemakers with a Turkish or Moroccan background was worse than the health status of homemakers with another ethnic background may reflect a lower acculturation.

Differences in migration experiences may also contribute to the differences in health between the ethnic minority groups. Refugees have a different migration history than Turks, Moroccans, Surinamese, and Antilleans. For refugees, experiences of violence, the flight to asylum and forced broken social networks may have affected health (Sundquist 1995). However, in this study we found that refugees had a relatively good health compared with the other ethnic minority groups. The relatively good health of refugees can partly be explained by the relatively high educational levels of refugees relative to the other ethnic minority groups.

Employed migrants are still concentrated in blue collar jobs in industry (Elkeles and Seifert 1996). Especially for employed refugees, who have a relatively high educational level (87\% intermediate/high educated) compared to the employed native Dutch (77\% intermediate/high educated), adverse health effects of unsatisfactory jobs have been suggested (Smith 2000). An Australian study has shown that unsatisfactory jobs can be as depressing as unemployment (Graetz 1993). Unfortunately, information about the potential misfit between personal capabilities and job requirements was not collected in the current study.

It was hypothesised that the associations of poor health and employment status would be less profound in ethnic groups with a high prevalence of unemployment compared to the Dutch population. When the unemployment rate is high, the effect of health selection out of the workforce is relative small compared to other factors that determine labour opportunities for people (Fayers and Sprangers 2002). In general, our results indeed showed that the association between unemployment and poor health was strongest in the Dutch population $(\mathrm{OR}=3.2)$ with the lowest unemployment, whereas the associations between unemployment and health were less profound in ethnic minority groups (ORs between 1.6 and 2.6), which were characterised by a higher unemployment level. In the current study the logistic regression analysis showed that the association between unemployment and health was not statistically significant 
Table 4 Associations between unemployment and poor health within different ethnic backgrounds in a community-based health survey in the Netherlands $(n=1,558)$

\begin{tabular}{ll}
\hline & OR $(95 \%$ CI $)$ \\
\hline Age & 1 \\
$18-24$ years & $1.9(1.1-3.6)$ \\
$25-44$ years & $4.2(2.3-8.0)$ \\
$45-55$ years & $4.1(2.2-7.9)$ \\
$55-64$ years & $1.6(1.2-2.2)$ \\
Women & \\
Educational level & 1 \\
High & $1.8(1.1-3.1)$ \\
Intermediate & $3.7(2.3-6.0)$ \\
Low & 1 \\
Native Dutch & $4.3(2.4-7.4)$ \\
Turkish/Moroccan & $2.8(1.8-4.3)$ \\
Surinamese/Antillean & $2.0(0.9-4.1)$ \\
Refugee & \\
Effect of unemployment within ethnic group & $3.2(1.9-5.4)$ \\
Native Dutch & $1.6(0.7-3.7)$ \\
Turkish/Moroccan & $2.6(1.3-5.2)$ \\
Antillean/Surinamese & $1.6(0.4-6.2)$ \\
Refugee & \\
\hline Enployed fulltime and & \\
\hline
\end{tabular}

Employed (full-time and part-time) and unemployed persons were included, whereas homemakers and disabled persons $(n=327)$ were not included in this analysis

$O R$ odds ratio, $C I$ confidence interval

within the Turkish/Moroccan group. However, when adjustment for gender and educational level did not take place, a significant association between unemployment and health $(\mathrm{OR}=2.5)$ was found. Hence, the absence of health inequalities across employment status within this ethnic group may be explained by the strong correlations between gender and employment status and between educational level and employment status. These additional analyses showed that especially female, low educated Turkish/ Moroccan persons were often unemployed and also reported the highest occurrence of a poor health.

The PAF of unemployment in poor health within the four ethnic groups varied between $13 \%$ among refugees to $26 \%$ among Surinamese/Antillean subjects. The PAF values among Dutch persons (14\%) was strongly influenced by the high OR for unemployment, whereas the PAF values among the ethnic minority groups were more influenced by the high prevalence of unemployment. Although this crosssectional study does not permit conclusions on causality, these findings suggest that, under the assumption that unemployment leads to a poor health, health inequalities related to unemployment are a major public health problem in all ethnic groups. Thus, policies for health equity should pay more attention to measures that include persons with a poor health in the labour market and that prevent workers with ill health from dropping out of the workforce.

Acknowledgments Funding for this study was provided by the Public Health (Fonds OGZ).

Open Access This article is distributed under the terms of the Creative Commons Attribution Noncommercial License which permits any noncommercial use, distribution, and reproduction in any medium, provided the original author(s) and source are credited.

\section{References}

Agyemang C, Denktas S, Bruijnzeels M, Foets M (2006) Validity of the single-item question on self-rated health status in first generation Turkish and Moroccans versus native Dutch in the Netherlands. Public Health 120:543-550. doi:10.1016/j.puhe.2006. 03.002

Alavinia SM, Burdorf A (2008) Unemployment and retirement and illhealth: a cross-sectional analysis across European countries. Int Arch Occup Environ Health 82:39-45. doi:10.1007/s00420-008-0304-6

Bartley M, Sacker A, Clarke P (2004) Employment status, employment conditions, and limiting illness: prospective evidence from the British household panel survey 1991-2001. J Epidemiol Community Health 58:501-506. doi:10.1136/jech.2003.009878

Boot CR, Heijmans M, van der Gulden JW, Rijken M (2008) The role of illness perceptions in labor participation of the chronically ill. Int Arch Occup Environ Health 82:13-20. doi:10.1007/s00420007-0298-5

Bos V, Kunst AE, Keij-Deerenberg IM, Garssen J, Mackenbach JP (2004) Ethnic inequalities in age- and cause-specific mortality in The Netherlands. Int J Epidemiol 33:1112-1119. doi:10.1093/ije/dyh189

CBS (2003) Herkomst van personen; allochtonen en migratie [Country of origin of persons; migrants and migration]. Centraal Bureau voor de Statistiek, Voorburg/Heerlen, Netherlands

Chandola T (2001) Ethnic and class differences in health in relation to British South Asians: using the new National Statistics SocioEconomic Classification. Soc Sci Med 52:1285-1296. doi:10.1016/S0277-9536(00)00231-8

Claussen B (1999) Health and re-employment in a five-year follow-up of long-term unemployed. Scand J Public Health 27:94-100

Dunn JR, Dyck I (2000) Social determinants of health in Canada's immigrant population: results from the National Population Health Survey. Soc Sci Med 51:1573-1593. doi:10.1016/S02779536(00)00053-8

Elkeles T, Seifert W (1996) Immigrants and health: unemployment and health-risks of labour migrants in the Federal Republic of Germany, 1984-1992. Soc Sci Med 43:1035-1147. doi:10.1016/ 0277-9536(96)00048-2

Fayers PM, Sprangers MA (2002) Understanding self-rated health. Lancet 359:187-188. doi:10.1016/S0140-6736(02)07466-4

Graetz B (1993) Health consequences of employment and unemployment: longitudinal evidence for young men and women. Soc Sci Med 36:715-724. doi:10.1016/0277-9536(93)90032-Y

Janlert U (1997) Unemployment as a disease and diseases of the unemployed. Scand J Work Environ Health 23(Suppl 3):79-83

Kuilman M, van Dijk AP, van der Lee G, Schrijvers CTM (2005) Resultaten gezondheidsenquete Rotterdam 2003 [Results health questionnaire Rotterdam 2003]. GGD Rotterdam, Rotterdam

Last JM (2001) A dictionary of epidemiology, 4th edn. Oxford University Press, New York

Marmot MG, Smith GD, Stansfeld S, Patel C, North F, Head J et al (1991) Health inequalities among British civil servants: the 
Whitehall II study. Lancet 337:1387-1393. doi:10.1016/01406736(91)93068-K

Morris JK, Cook DG, Shaper AG (1994) Loss of employment and mortality. BMJ 308:1135-1139

Nazroo JY (2003) The structuring of ethnic inequalities in health: economic position, racial discrimination, and racism. Am J Public Health 93:277-284. doi:10.2105/AJPH.93.2.277

Schuring M, Burdorf A, Kunst AE, Mackenbach JP (2007) The effect of ill health on entering and maintaining paid employment: evidence in European countries. J Epidemiol Community Health 61:597-604. doi:10.1136/jech.2006.047456

Smith GD (2000) Learning to live with complexity: ethnicity, socioeconomic position, and health in Britain and the United States. Am J Public Health 90:1694-1698. doi:10.2105/AJPH.90. 11.1694

Smith GD, Chaturvedi N, Harding S, NazRoo J, Williams R (2000) Ethnic inequalities in health: a review of UK epidemiological evi- dence. Crit Public Health 10:375-408. doi:10.1080/095815 90010005331

Sundquist J (1995) Ethnicity, social class and health. A populationbased study on the influence of social factors on self-reported illness in 223 Latin American refugees, 333 Finnish and 126 south European labour migrants and 841 Swedish controls. Soc Sci Med 40:777-787. doi:10.1016/0277-9536(94)00146-K

Uniken Venema HP, Garretsen HF, van der Maas PJ (1995) Health of migrants and migrant health policy, The Netherlands as an example. Soc Sci Med 41:809-818. doi:10.1016/0277-9536(95)00065-F

Ware JE Jr, Sherbourne CD (1992) The MOS 36-item short-form health survey (SF-36). I. Conceptual framework and item selection. Med Care 30:473-483. doi:10.1097/00005650-199206000-00002

Wiking E, Johansson SE, Sundquist J (2004) Ethnicity, acculturation, and self reported health. A population based study among immigrants from Poland, Turkey, and Iran in Sweden. J Epidemiol Community Health 58:574-582. doi:10.1136/jech.2003.011387 